\section{Centro de Memória do Vasco da Gama: entrevista com João Ernesto da Costa Fer- reira e Adílio Jorge Marques}

The Centro de Memória (Memory Center) of Vasco da Gama

\section{Elcio Loureiro Cornelsen}

Universidade Federal de Minas Gerais (UFMG), Belo Horizonte/Brasil Doutor em Germanística, Freie Universität Berlin

emcor@uol.com.br

\section{Gustavo Cerqueira Guimarães}

Universidade Federal de Minas Gerais (UFMG), Belo Horizonte/Brasil Doutor em Teoria da Literatura e Literatura Comparada, UFMG

\section{Marcus Vinícius Costa Lage}

Universidade Federal de Minas Gerais (UFMG), Belo Horizonte/Brasil

Doutorando em História, UFMG
RESUMO: Entrevista concedida em conjunto pelo vicepresidente de relações especializadas do Club de Regatas Vasco da Gama, o engenheiro João Ernesto da Costa Ferreira, e pelo diretor de acervo do Centro de Memória do Clube, o professor da Universidade Federal dos Vales do Jequitinhonha e Mucuri, doutor em História, Adílio Jorge Marques.

Palavras-chave: Centro de Memória do Vasco da Gama; Futebol e memória; Futebol e Edição; Narrativas de futebol.

ABSTRACT: Interview granted jointly by the Vice-president of Specialized Relations of the Club de Regatas Vasco da Gama, engineer João Ernesto da Costa Ferreira, and the director of the Club Memory Center Collection, the professor of the Universidade Federal dos Vales do Jequitinhonha e Mucuri, Doctor of History, Adílio Jorge Marques.

KEYwoRDS: Memory Center of Vasco da Gama; Football and memory; Football and Edition; Football Narratives. 
FuLiA / UFMG: Desde quando o Club de Regatas Vasco da Gama possui um Centro de Memória e o que motivou sua criação?

Centro de Memória do Vasco da Gama: Não temos uma data precisa antes de 2008. Embora houvesse, sob a parte Social do estádio de São Januário, uma pequena sala em cuja porta havia a inscrição "Centro de Memória”, foi com a chegada à Diretoria, nesse mesmo ano, de João Ernesto (vicepresidente de Relações Especializadas na época, e hoje novamente à frente desse setor) que pela dinâmica de trabalho ali implantada, aquela denominação passou a ter valor.

Quanto à motivação, não haveria outra maior do que não a de ser o fiel depositário do maior patrimônio do clube, o patrimônio histórico, dando-lhe o tratamento e o acondicionamento digno, compatível com a rica história do Club de Regatas Vasco da Gama. 0 clube sempre esteve à frente de seu tempo. Foi o responsável pela construção do maior estádio da América do Sul em 1927, sempre cedeu jogado- res para a seleção brasileira de futebol, além de patrocinar vários esportes amadores.

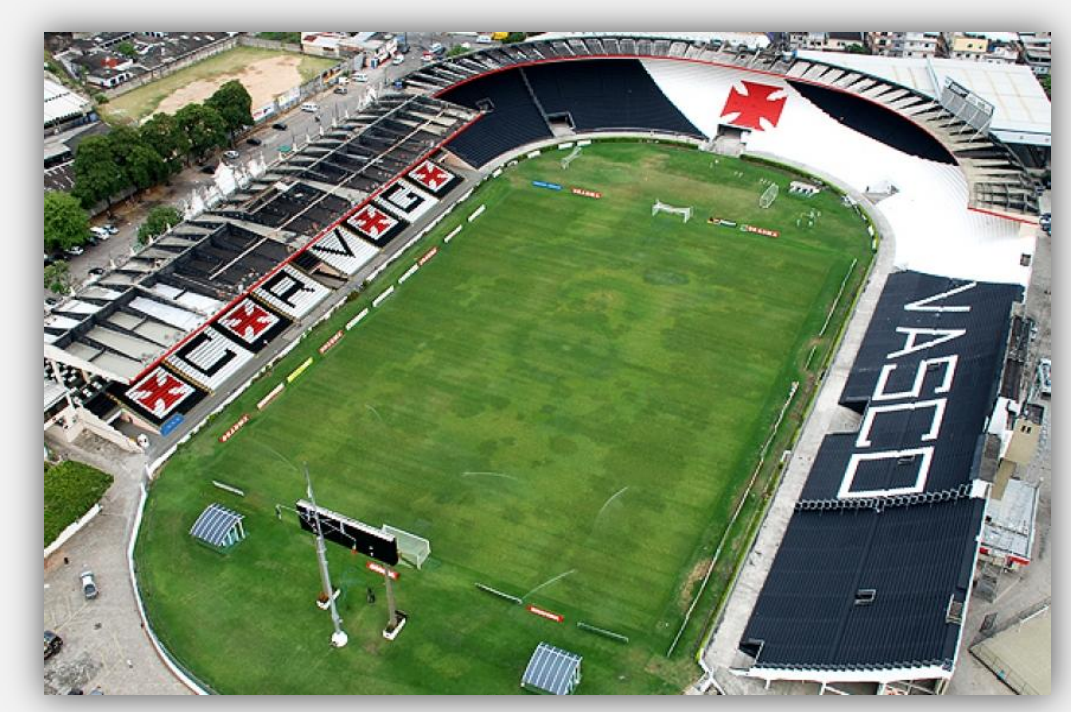

Estádio São Januário. Fotografia: site do clube.

E, talvez uma das maiores contribuições, senão a maior: defender 12 atletas pobres, mulatos e negros em 1924 da discriminação que havia no futebol do RJ, a vitrine para o país pelo fato de ser a capital do Brasil. 0 documento de 1924 ficou conhecido como "A Resposta Histórica", em virtude de os dirigentes dos clubes rivais na cidade resolve- 
rem "investigar" as atividades profissionais e sociais dos atletas vascaínos, uma vez que o futebol ainda era amador e os jogadores não poderiam receber salários.

FuLiA / UFMG: E do que se tratava tal documento?

Centro de Memória do Vasco da Gama: Em resumo, ele surgiu da tentativa de retirar o Vasco da Gama da disputa dos campeonatos de futebol. 0 instrumento para essa tentativa foi o regulamento da "Liga Metropolitana", quando os principais clubes cariocas partiram para a criação de uma nova entidade, a "Associação Metropolitana de Esportes Athléticos (AMEA)", passando a recusar a inscrição dos vascaínos. Segundo os dirigentes adversários, o time do Vasco seria composto por atletas de profissão duvidosa, e o clube também não contava com um estádio em boas condições.

Nesse contexto, a AMEA solicitou ao Vasco que excluísse 12 de seus jogadores da competição, que, por coincidência, eram todos negros e operários. O Club de Regatas Vasco da Gama recusou a proposta e, por meio de uma carta histórica de seu presidente, o Sr. José Augusto Prestes, mos- trou sua total indignação: "Estamos certos de que Vossa Excelência será o primeiro a reconhecer que seria um ato pouco digno de nossa parte sacrificar, ao desejo de filiar-se à $A M E A$, alguns dos que lutaram para que tivéssemos, entre outras vitórias, a do Campeonato de Futebol da Cidade do Rio de Janeiro de 1923 (...) Nestes termos, sentimos ter de comunicar a Vossa Excelência que desistimos de fazer parte da AMEA". Restou ao Vasco disputar, com outros clubes, o campeonato na Liga Metropolitana de Desportos Terrestres. Assim, nesse dia histórico, o futebol brasileiro começou a ser de todo o povo, e não apenas da elite que havia trazido em suas bagagens o esporte bretão para o Brasil.

FuLiA / UFMG: Como o Centro de Memória se estrutura? Além de memorabília, ele também conta com acervo e arquivo documental?

CMVG: Hoje, o Centro de Memória (CM) ${ }^{1}$ contempla quatro atividades: o tratamento do "Acervo", o "Salão de Troféus", o projeto do "Museu do Vasco da Gama" (que está em plane-

\footnotetext{
${ }^{1}$ Abreviatura utilizada: $\mathrm{CM}=$ Centro de Memória.
} 
jamento), e a visita guiada pelo Complexo Esportivo de São Januário, o que denominamos "Tour pela Colina Histórica".

O "Acervo" é composto de milhares de documentos e imagens, todos das mais diversas fontes, tratados e digitalizados de forma profissional. Além dos documentos já existentes no Club, temos aqueles que recebemos de vários lugares do Brasil quase todas as semanas. A torcida do Vasco da Gama é muito grande e ativa, além de possuir a característica, na sua grande maioria, de dar grande valor ao aspecto histórico de nossa centenária instituição. Há, também, visitas em centros de arquivo, sempre em busca de novas informações sobre o Vasco da Gama, a história do futebol local e nacional, e mesmo dos demais esportes que tenham tido relevância para o Vasco ou para o país (remo e basquete, por exemplo).

O "Salão de Troféus" é composto de milhares de peças, oriundas de conquistas nacionais e internacionais dos mais diversos esportes, desde o final do século XIX.
Estamos a planejar um futuro "Museu do Vasco da Gama", provavelmente nas dependências de São Januário, mas ainda não temos mais informações para fornecer. Estamos buscando patrocínio, pois queremos que seja nos mesmos moldes daqueles existentes na Europa, nos seus grandes clubes.

O "Tour pela Colina Histórica" é um projeto que se iniciou em agosto deste ano (2018) como um dos marcos das comemorações dos 120 anos do Vasco da Gama. Um passeio que proporciona aos torcedores, sócios e visitantes em geral a oportunidade de realizar uma visita guiada de 50 a 60 minutos por todo o Complexo Esportivo de São Januário, incluindo o vestiário dos jogadores. Uma verdadeira viagem pela história do clube: Busto do Almirante / Salão de Troféus / Tribuna de Honra / Ginásio Vasco da Gama / Vestiário do Futebol Profissional / Estátua do Gol Mil Romário / Painel de Ídolos / Colégio Vasco da Gama / Capela Nossa Senhora das Vitórias / Parque Aquático / Megaloja do Vasco. 
O Tour funciona de segunda a sábado, em horários prédefinidos, com grupos de no máximo 30 pessoas. 0 ingresso deverá ser adquirido na recepção do Tour, localizada na entrada principal do Estádio. 0 agendamento para a visitação pode ser feito pelo telefone do Centro de Memória do clube: (21) 2176-7390. Essa programação não há aos domingos, feriados e em dias de jogos em São Januário.

A dar conta dessas várias tarefas, temos dois diretores (professor Adílio Jorge Marques e Fernando Lopes), um historiador (Walmer Peres Santana), uma secretária, dois guias de turismo, dois atendentes (Salão de Troféus e Tour), um controlador dos troféus e um auxiliar de serviços gerais, além de quatro estagiários de História oriundos de cursos regulares de graduação.

Comumente, recebemos artigos que tratem da história em geral do Vasco da Gama, e não apenas do futebol. Desde, por exemplo, relatórios da Federação de Remo do Rio de Janeiro, até carteiras de antigos sócios, jornais e flâmulas.
Basta buscar nosso contato no CM acima mencionado e/ou nos procurar pelo site oficial: http://www.vasco.com.br/site.

FuLiA / UFMG: Antes da criação do Centro de Memória, havia programas ou estratégias de preservação da memória do clube? Se sim, como eles se estruturavam?

CMVG: Antes do CM, somente duas atividades significativas contribuíam para a preservação da memória do Clube: o Salão de Troféus e a inserção em Livros de Registro das súmulas do futebol vascaíno. As Atas da Diretoria, de uma forma involuntária e mesmo secundária, acabaram por se tornar documentos internos da movimentação de alguns setores do clube.

FuLiA / UFMG: Como vocês consideram, em termos de preservação em geral, a relação entre futebol e memória no Brasil?

CMVG: Considerando os grandes clubes brasileiros, cremos que, com a organização que temos hoje no CM do clube, somos pioneiros neste segmento. Todavia, a despeito desse pioneirismo, vemos isso com certa tristeza, pois a preservação da memória de uma instituição é de fundamental impor- 
tância para a manutenção dela. Não sendo assim, de forma sistematizada, restarão tão somente os arquivos jornalísticos, cujas empresas estão sujeitas às intempéries das crises de mercado, e a transmissão oral, particularmente a familiar, cuja fidelidade com o fato nem sempre é observada.

Lembramos aqui o famoso historiador francês, Jacques Le Goff, quando ele menciona em sua obra História e Memória que o ato de rememoração requer um comportamento narrativo e de certa constância; deve ser construído, pois se trata da comunicação a outrem de informações. Quem não cuida de sua memória não pode atender ao aspecto básico da sua constituição: saber quem ele é. Enfim, o CM busca preservar os sentimentos de pertencimento dos brasileiros, em especial, dos torcedores vascaínos, reforçando os seus símbolos e as suas imagens. Quem não identifica, por exemplo, na sua cruz vermelha, inspirada na portuguesa Ordem de Cristo, um de seus marcos de reconhecimento?
Por isso, o Vasco da Gama busca manter viva a memória do esporte no Brasil e no mundo, além, claro, de reforçá-la sempre junto aos seus torcedores.

FuLiA / UFMG: O Vasco da Gama é considerado, tanto em obras de cunho memorialístico, quanto em trabalhos acadêmicos, um dos clubes pioneiros no processo de popularização do futebol carioca e brasileiro. Como vocês tratam essa questão no Centro de Memória do clube?

CMVG: Com a máxima valorização, até porque como a formulação da pergunta já explicita, a rica história do Vasco da Gama é um manancial para todo aquele que queira entender como as ações desse clube mudaram, de forma substancial, o esporte brasileiro, como mencionamos antes.

Tão gloriosa no campo esportivo quanto a dos demais clubes coirmãos, a história vascaína é única naquilo em que ela construiu para além dos gramados do futebol, das quadras, das raias das piscinas, das pistas de atletismo, e de suas atividades sociais. Exemplos dados à sociedade brasileira de que, naquela Casa, não haveria - e não há - distin- 
ção de cor, credo ou situação econômica, sendo estas marcas genuinamente vascaínas. Marcas das quais todos temos imenso orgulho. A nossa reverência é constante, e será eterna, aos nossos avós e bisavós, os grandes responsáveis pela edificação de um Gigante do desporto nacional.

FuLiA / UFMG: A qual público se destina o Centro de Memória do Vasco da Gama? Vocês fazem algum tipo de avaliação ou levantamento desses visitantes?

CMVG: 0 CM, pela natureza da sua atividade, não é um espaço de visitação permanente. 0 acesso a ele é restrito, pois parte de nosso acervo está acondicionado em ambiente especializado, como o de grandes bibliotecas. Entretanto, essa atividade não teria sentido de existir se não a compartilhássemos com o vascaíno, em geral, e com os estudiosos, em particular.

De modo a atender a esse último segmento mencionado, reuniões previamente agendadas materializam esse contato, para todo aquele que queira conhecer o nosso rico acervo. E, também, podemos dizer que estamos em fase final de um site do CM, o "Memória Vasco". Neste sítio digital, qualquer vascaíno, professor, pesquisador, e o público em geral, mesmo no mais distante ponto do planeta, poderá desfrutar do maravilhoso arquivo digital que iremos disponibilizar, nos mesmos moldes da Biblioteca Nacional. Acreditamos que ele estará disponível em breve, também com link pelo site principal do clube.

FuLiA / UFMG: Como é a integração do Centro de Memória com os demais usos do estádio e clube social do Vasco?

CMVG: O CM, além da sua atividade-fim, atua como suporte às demandas dos mais diversos departamentos do clube, seja da Presidência, Engenharia, Marketing, ou até mesmo do Social. De forma oficial, quem responde pela história do Vasco da Gama e dá suporte às atividades que dependam dela, é o nosso Centro de Memória. Garantimos apoio técnico a projetos de memória esportiva, em especial aqueles ligados ao Vasco, e assim mantemos viva a chama do resgate da trajetória da nossa importante instituição. Com isso, garantimos o suporte para ações de comunicação e marke- 
ting, contribuindo para o fortalecimento de nossa identidade corporativa, da marca e das relações com o público.

FuLiA / UFMG: Os livros que tematizam os clubes de futebol, sejam eles biográficos, históricos, jornalísticos, literários ou estatísticos, também contribuem muito para a preservação e propagação da memória clubística no país. Sobre o Vasco foi produzida uma qualificada e diversificada bibliografia. Como bons exemplos, podemos citar um dos livros que trata da história do clube, Vasco: a cruz do BacaIhau (2009), do renomado compositor Aldir Blanc em parceria com o jornalista José Reinaldo Marques, e o livro de poesia 38 círculos (2010), de Luis Maffei, professor de Literatura Portuguesa da UFF, que traz 38 poemas, um por jogo, sobre a campanha do Vasco no Campeonato Brasileiro da Série B de 2009. Quais outros principais títulos de livros vascaínos poderiam ser destacados?

CMVG: Temos uma vasta literatura a respeito do clube e de sua memória, inclusive na luta contra o racismo, apesar de pouco divulgada no Brasil. Podemos citar alguns títulos interessantes, como por exemplo: Os dez mais do Vasco da Gama (2014), de Rodrigo Taves e Claudio Nogueira, temos o recorte de uma seleção de dez grandes craques que imortalizaram o clube no cenário do futebol. Ainda nessa linha há o conhecido livro de Paulo César O. Pinto, Um ídolo chamado Roberto Dinamite (1987), sobre o maior (ou um dos maiores) jogadores do Vasco da Gama. Destaco, ainda, Jogos memoráveis do Vasco (2012), coleção “Grandes Jogos” dos autores Alexandre Mesquita, Eugênio Leal e Jefferson Almeida. Interessante abordagem sobre algumas das mais marcantes partidas de futebol da história do Vasco, de 1923 com o jogo do primeiro título carioca a 2011 com a conquista da Copa do Brasil. Interessante a pouco conhecida obra A história do Vasco da Gama em cordel (2003), de Claudio Aragão, da coleção Futebol em Cordel, pois possui uma abordagem da história do Vasco pela visão de uma das mais interessantes abordagens culturais do Brasil, a literatura de cordel. O livro Nasce o Gigante da Colina (2014), de Pedro Venancio, é interessante por abordar as origens vascaínas desde 1898 até a formação do seu time de futebol e 
os anos 1920. Em O time do meu coração - Club de Regatas Vasco da Gama (2009), Claudio Nogueira trata, em uma breve obra de divulgação e de fácil acesso comercial, de aspectos gerais como torcedores ilustres, torcedores e jogadores de maior destaque. Temos a obra $A$ virada do século (2009), de Camilo Sepúlveda, sobre o histórico jogo do ano de 2000 quando o Vasco da Gama conquistou a Copa Mercosul sobre a equipe do Palmeiras, jogando na casa do adversário, após estar perdendo por 3 a 0 até os 14 minutos da segunda etapa. No fim, o Vasco virou para 4 a 3 em uma das mais marcantes vitórias em finais da história do futebol. Ainda Monumental - O Vasco de 1997 a 2000 (2017), de Thiago Correia, a contar a história a fase vitoriosa do clube entre esses anos. Paixão da Gama: a maraviIhosa história do Vasco (2011), Jorge Luiz Alves Bezerra, obra repleta de acontecimentos notáveis do Club de Regatas Vasco da Gama, organizada cronologicamente. Por fim, lembramos o livro da cantora e vascaína Teresa Cristina, $O$ dia em que me tornei... vascaína (2011), relato interessante e para jovens de uma paixão pelo Vasco da Gama.

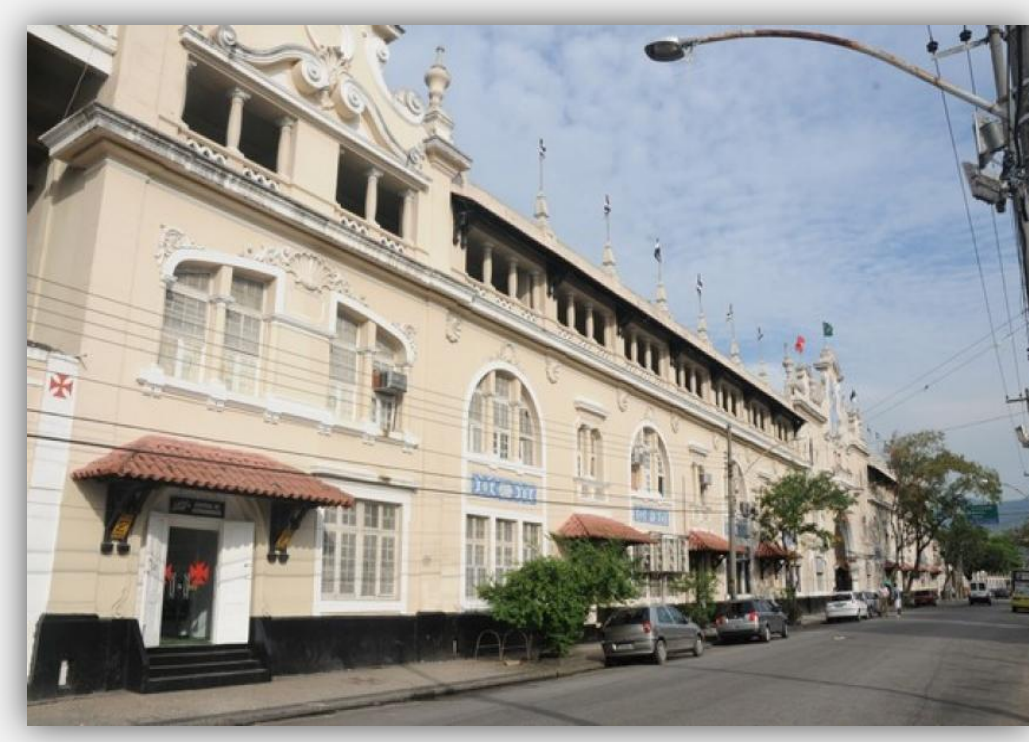

A fachada de São Januário, com 274 m de extensão, é tombada pelo Patrimônio Histórico e Artístico Nacional. Imagem: site do clube.

Entrevista concedida no dia 08 de setembro de 2018. 